\title{
Neural manifestation of cognitive and precognitive mismatch detection in early infancy
}

\author{
Angela D. Friederici, ${ }^{C A}$ Manuela Friedrich and Christiane Weber \\ Max Planck Institute of Cognitive Neuroscience, PO. Box 500 355, 04303 Leipzig, Germany \\ ${ }^{\mathrm{CA}}$ Corresponding Author
}

Received I 4 March 2002; accepted 10 May 2002

\begin{abstract}
We recorded event-related potentials (ERPs) in 2-month-old infants in two different states of alertness: awake and asleep. Syllables varying in vowel duration (long vs short) were presented in an oddball paradigm, known to elicit a mismatch brain response. ERPs of both groups showed a mismatch response reflected in a positivity followed by a frontal negativity. While the positivity was present as a function of the stimulus type (present for long
\end{abstract}

deviants only), the negativity varied as a function of the state of alertness (present for awake infants only). These data indicate a functional separation between precognitive and cognitive aspects of duration mismatch essential for the distinction between long and short vowels during early infancy. NeuroReport 13:125I-1254 (c) 2002 Lippincott Williams \& Wilkins.

Key words: Auditory perception; Infants; Mismatch negativity (MMN); Phoneme discrimination; Vowel duration

\section{INTRODUCTION}

Language comprehension crucially depends on the hearer's ability to discriminate between different phonemes. There are numerous studies indicating that the adult brain produces a response as early as $100-200 \mathrm{~ms}$ after stimulus onset in a so-called oddball paradigm (for a recent review see [1]). This response is a negative component which is elicited by any discriminable change (deviant) in some repetitive (standard) aspect of auditory stimulation, named mismatch negativity (MMN) [2]. The MMN has been interpreted to reflect the detection of a deviance in the auditory input from information established in sensory memory. This auditory process itself is assumed to be preperceptual but to trigger frontal cortex activity (reflected by the frontal MMN subcomponent) in adults [3,4]. The MMN appears to depend on the state of alertness as it has been shown to disappear during sleep stage 2-4 of the adult [5-9]. Instead of a negativity some researchers observed a positivity around $250 \mathrm{~ms}$ during sleep [10,11]. The neural process underlying this positivity has been interpreted by some researchers to reflect selective refractoriness [12,13].

The oddball paradigm has been used to investigate the sensitivity to phonemic contrasts in normal infants [14-16] as well as infants at risk for dyslexia $[17,18]$. Some of these studies reported a negativity as a mismatch response [15,19] whereas others reported a positivity [16-18]. It is not clear, however, what determines the polarity of the observed mismatch response. Given the data from adult hearers the question arises whether the state of alertness in infants may have an influence on the mismatch response. While some of the infant studies clearly state that their participants were either asleep [17] or awake [20] during ERP recording, others seem to have mixed recordings from awake and asleep infants [21] or did not report the infants' cognitive state [16].

The present study systematically separated a group of asleep infants from awake infants in an ERP study applying a mismatch negativity paradigm. This paradigm which has been shown to tap the automatic ability to detect changes in a stimulus stream was used to investigate the infants ability to detect vowel duration changes in a consonant vowel syllable /ba/vs /ba:/. Vowel duration is a critical phonemic difference in German, the target language of our participants. In German the duration of a vowel is a discriminative feature indicating differences in meaning: for example the word /la:m/, lahm (lame) vs the word /lam/, Lamm (lamb). In contrast to earlier studies on vowel duration which only used the short syllable as a deviant $[17,18]$ the present study used both the short and the long syllable as a deviant in two different experimental conditions.

\section{SUBJECTS AND METHODS}

Participants: The present study is part of the German Language Development Study (GLaD, www.glad-study.de) established at the Children's Hospital Lindenhof, Charité, Medical Faculty of the Humboldt University Berlin. Families expecting a baby were contacted and requested to participate in the study according to institutional informed consent procedures. The infants were healthy and without neurological or developmental problems (according to Prechtl and Griffiths scales). The recordings were taken when the infants were 8 weeks ( \pm 5 days) old. Prior to the experiment the infants hearing was tested by an 
otoacoustic emission screening (OAE). All children had a normal hearing. A total of 39 infants entered the study as they were identified to either be awake in an experimental run or asleep. Twenty-nine infants (10 female) were asleep whereas only 10 infants (four female) remained awake during a whole experimental run.

Procedure, stimuli and ERP recording: In a passive oddball paradigm (standard: $p=5 / 6$, deviant: $p=1 / 6$ ) two experimental runs were created: (1) a frequently occurring short CV-syllable (/ba/, duration $202 \mathrm{~ms}$ ) was occasionally replaced by a deviant, i.e. a long CV-syllable (/ba:/, duration $341 \mathrm{~ms}$ ) and (2) a frequently occurring long CVsyllable /ba:/ replaced by an occasionally occurring short CV-syllable / ba/.

The short syllable /ba/ was infant directed spoken by a young mother who is a native speaker of standard German. After recording and digitalization $(44.1 \mathrm{kHz}, 16$ bit sampling rate) the steady state part of the vowel was lengthened (starting $30 \mathrm{~ms}$ after syllable onset) to obtain the second syllable /ba:/ (Fig. 1). During each experimental run 600 trials were presented with a fixed ISI (offset to onset) of $855 \mathrm{~ms}$. The order of the two runs was counterbalanced across the infants. Stimuli were presented via a loudspeaker with an intensity of $64 \mathrm{~dB}$ SPL. The infants were lying in a child's safety seat while ERP were recorded. Their alertness state was determined every $2 \mathrm{~min}$ by both the infants monitored behavior and the on-line EEG.

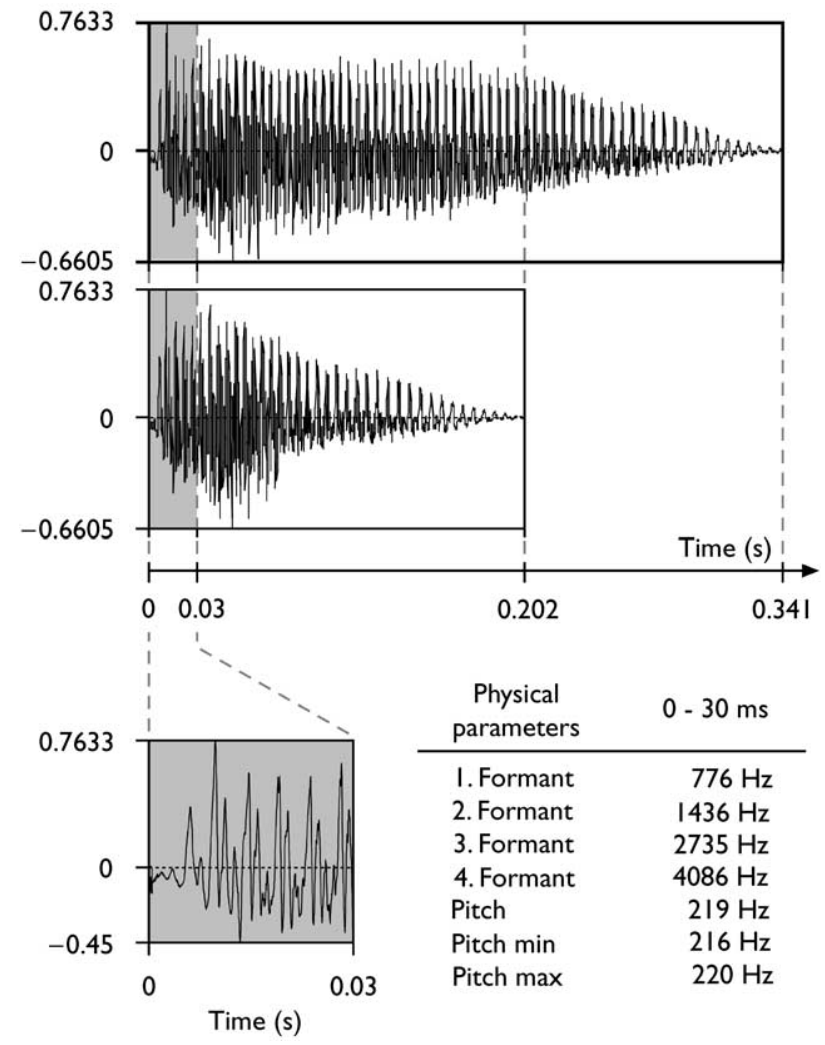

Fig. I. Stimulus plot. Short naturally produced syllable (below) and lengthened syllable (above).
The ERPs were registered with Ag-AgCL electrodes attached to frontal $(\mathrm{F} 3, \mathrm{Fz}, \mathrm{F} 4)$, central $(\mathrm{C} 3, \mathrm{Cz}, \mathrm{C} 4)$ and parietal (P3, Pz, P4) scalp sites according to the International 10-20 electrode system. An electrode cap was used. Electrooculograms (EOG) were bipolar recorded from supraorbital and infraorbital electrodes on the right eye as well as from electrodes located lateral to the left and to the right eye. The ERP electrodes were referred to A1. The EEG was amplified with PORTI-32/MREFA (Twente Medical Systems), digitalized on-line at a rate of $250 \mathrm{~Hz}$, and stored on hard disk. Further analyses were processed off-line. The EEG was high-pass filtered with $0.3 \mathrm{~Hz}$ and algebraically rereferred to the average of both mastoids. Trials with a s.d. $>80 \mu \mathrm{V}$ within a sliding window of $200 \mathrm{~ms}$ were rejected automatically. Epochs of $1000 \mathrm{~ms}$ from stimuli onset were averaged according to a $200 \mathrm{~ms}$ pre-stimulus baseline. At least 60 artifact free trials were required for an individual average to be included in further analyses. The statistical analyses were carried out for consecutive time windows of $200 \mathrm{~ms}$.

A four-way ANOVA with the factors stimulus (long vs short), condition (deviant vs standard), site (F3/Fz/F4/C3/ $\mathrm{Cz} / \mathrm{C} 4 / \mathrm{P} 3 / \mathrm{Pz} / \mathrm{P} 4$ ) and group (awake vs asleep) as a random factor was conducted to reveal possible interactions of the experimental manipulated conditions with the alertness state. To separately determine the differences between standard and deviant one-way analyses with the factor condition were calculated for long and short stimuli within each group.

\section{RESULTS}

ERP differences between standard and deviant were found as a function of stimulus type and state of alertness in three different time windows (stimulus $\times$ conditions $\times$ group, 200-400 ms: $\mathrm{F}(1,8)=36.076, \quad p<0.001 ; \quad 600-800 \mathrm{~ms}$ : $\mathrm{F}(1,8)=7.073, \quad p=0.029 ; \quad 800-1000 \mathrm{~ms}: \quad \mathrm{F}(1,8)=16.381$, $p=0.004)$. In the fourth time window between 400 and $600 \mathrm{~ms}$ different processing of long and short stimuli within the standard and deviant conditions was not affected by the alertness state (stimulus $\times$ condition $\times$ group, $400-600 \mathrm{~ms}$ : $\mathrm{F}(1,8)=1.192, p>0.05)$.

Both the awake and the asleep group showed a mismatch response for the long deviant condition. For awake infants we observed a frontal positivity significant between 400 and $600 \mathrm{~ms}(\mathrm{Fz}: \mathrm{F}(1,18)=4.679, p=0.044)$ followed by a right frontally distributed negativity significant between 800 and $1000 \mathrm{~ms}(\mathrm{~F} 4: \mathrm{F}(1,18)=5.241, p=0.034$; Fig. 2a). Infants that were asleep (Fig. 2b) demonstrated a positivity which was spatially and temporally more extended than the one observed for the awake group (200-400 ms, Fz: $\mathrm{F}(1,56)=8.953, p=0.004 ; \mathrm{F} 3: \mathrm{F}(1,56)=8.068, p=0.006 ; \mathrm{F} 4$ : $\mathrm{F}(1,56)=8.008, p=0.006 ; \mathrm{Cz}: \mathrm{F}(1,56)=8.431, p=0.005 ; \mathrm{C} 3$ : $\mathrm{F}(1,56)=7.893, p=0.007 ; \mathrm{C} 4: \mathrm{F}(1,56)=6.644, p=0.013 ; \mathrm{Pz}:$ $\mathrm{F}(1,56)=7.689, p=0.008 ; \mathrm{P} 3: \mathrm{F}(1,56)=5.665, p=0.021 ; 400-$ $600 \mathrm{~ms}, \mathrm{Fz}: \mathrm{F}(1,56)=5.033, p=0.029 ; \mathrm{F} 3: \mathrm{F}(1,56)=4.739$, $p=0.034 ; \mathrm{F} 4: \mathrm{F}(1,56)=5.131, p=0.027 ; \mathrm{Cz}: \mathrm{F}(1,56)=4.390$, $p=0.041 ; C 3: F(1,56)=4.294, p=0.043)$. This difference between the groups might be caused by an overlapping non-significant negative deflection within the time window between 200 and $400 \mathrm{~ms}$ which can be observed for awake infants. In the asleep group, moreover, a late centro-parietal 


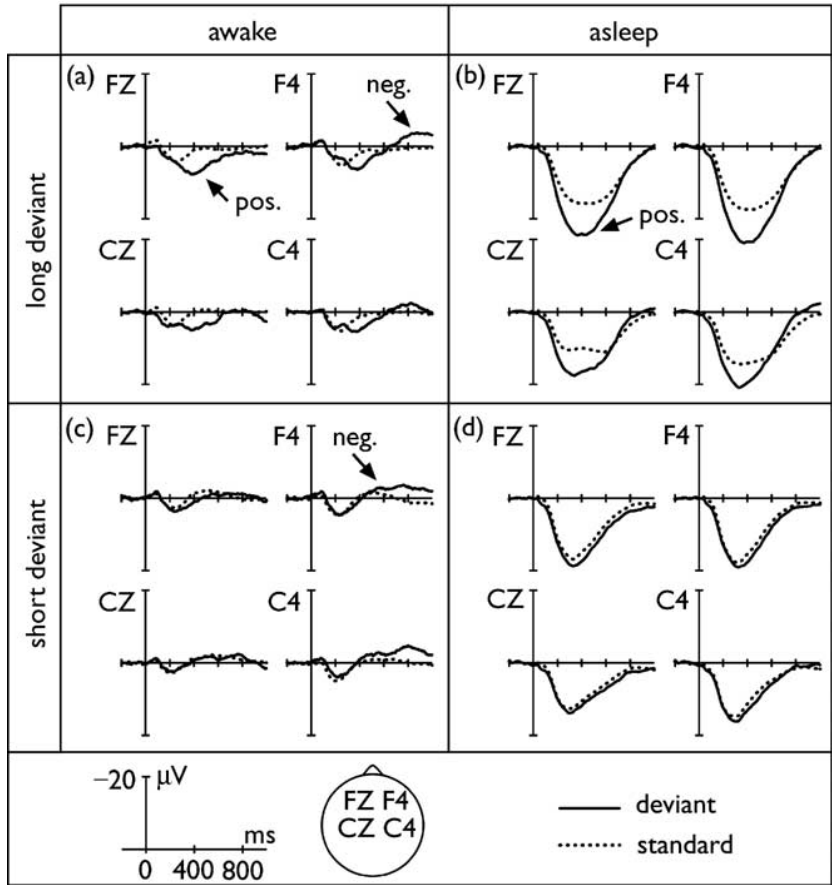

Fig. 2. Averaged ERPs to long deviants for 10 infants in awake state (a) and for 29 infants asleep (b), and to short deviants for 10 infants in awake state (c) and for 29 infants asleep (d). Solid lines for deviants and broken lines for standards. Pos. $=$ frontal positivity; Neg. = frontal negativity.

negativity was found to be significant at electrode $\mathrm{C} 4$ for the long deviant condition (800-1000 ms, $F(1,56)=4.996$, $p=0.029$ ). For a direct comparison of the two groups see Fig. 3.

For the short deviant neither group showed an effect in the positivity time range. Again, there was a group difference with respect to the negativity: awake infants (Fig. 2c) showed a right frontal negativity (F4: $\mathrm{F}(1,18)=8.038, p=0.011$ ) similar to that of the long stimulus, whereas asleep infants did not. For a direct comparison of the two groups see Fig. 3.

\section{DISCUSSION}

Clear differences were observed for phoneme change detection as a function of the infant's state of alertness and as a function of stimulus type (duration). Two different ERP components were observed as a mismatch response: a positivity with a frontal maximum peaking at $500 \mathrm{~ms}$ and a frontally distributed negativity with a maximum between 800 and $900 \mathrm{~ms}$. While the positivity varied as a function of stimulus type, the frontal negativity varied as a function of alertness.

The positivity was only present for long deviants clearly demonstrating that it is easier to detect a long syllable as a deviant in a sequence of short syllables than a short syllable as a deviant in a sequence of long syllables. This can be explained by a greater perceptual saliency of a larger element in the context of smaller elements than of a smaller element in the context of larger elements. The finding that the positivity was present for both groups indicates that this

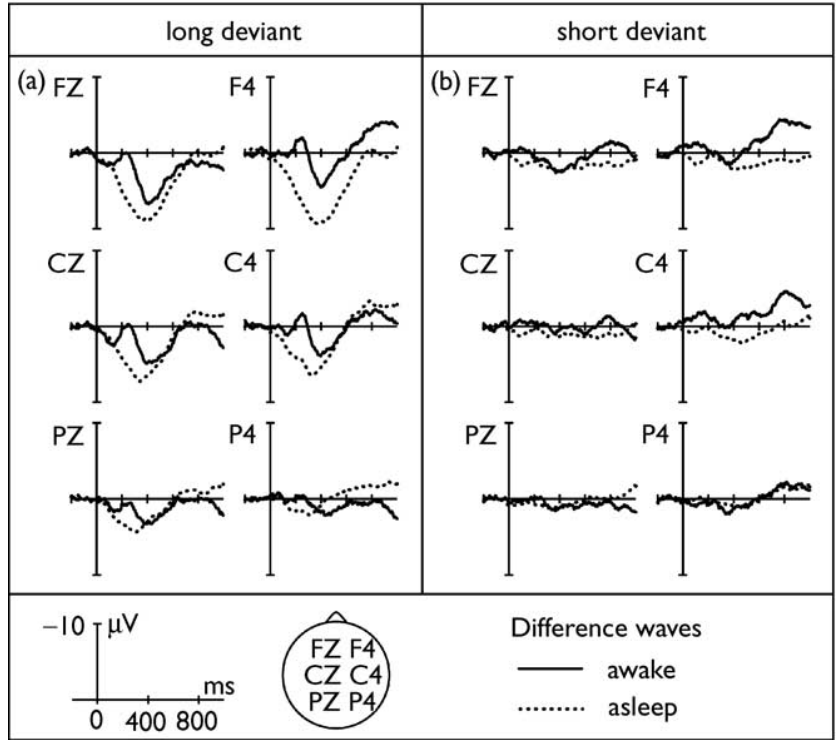

Fig. 3. Difference waves for 10 infants in awake state (solid lines) for 29 infants asleep (broken lines) and for long stimuli (a) and short stimuli (b).

effect reflects a precognitive aspect of change detection. The further result that the positive deflection for both deviant and standard condition was larger for infants that were asleep than for infants that were awake, furthermore, can be taken as additional evidence for the notion that the positivity reflects precognitive aspects of auditory processing.

The frontal negativity was present only for the awake group. This suggests that this negativity reflects an aspect of the mismatch response which is related to alertness and may therefore be viewed to reflect a cognitive aspect. A second late negativity with a centro-parietal maximum was observed to the long deviant for asleep infants. As this negativity's presence depends on both the stimulus type as well as on the infants' state of alertness it functionally resembles the late negativity reported for adults during sleep [22]. For adults a late negativity (N360) was observed as part of a biphasic pattern following a positivity (P240) in an auditory oddball paradigm, which also was modulated by the state of alertness and by the stimulus type with a larger amplitude for high than for low deviants.

The present results for the asleep infants are in general agreement with earlier findings [17]. In a study which only used a short syllable as a deviant and in which infants were asleep during ERP recordings, a positivity between 200 and $450 \mathrm{~ms}$ was found for 6-month-old Finnish infants [17]. This study also tested newborn infants for two ISI conditions. A similar positivity was not observed for both ISI conditions, but in an earlier window (155-200 ms) a positivity was found at P3 in the long ISI condition [18]. Thus, it appears that a mismatch response to duration decrements in vowels cannot easily be found at birth but it occurs in form of a positivity with a maximum between 200 and $450 \mathrm{~ms}$ at the age of 6 months [17]. At the age of 2 months a mismatch response to duration decrement could still not be observed 
in asleep infants (present study). However, at this age a positive mismatch response with a maximum between 400 and $600 \mathrm{~ms}$ occurred to the more salient duration increment (present study). The ability to discriminate different consonants in 4-month-old French infants was also reflected in a positive deflection present between 320 and $480 \mathrm{~ms}$ [16]. Unfortunately, this latter paper does not report the state of alertness of their participants.

Thus, the occurrence of the positive mismatch response not only depends on the age of the infants but also on the saliency of the deviant stimulus. Furthermore, the combined data from the different studies seem to indicate that the latency of the positivity as a mismatch response decreases as a function of age: $400-600 \mathrm{~ms}$ at the age of 2 months, 320$480 \mathrm{~ms}$ at the age of 4 months, 200-450 ms at the age of 6 months. This pattern is quite suggestive even though we are comparing findings across different languages and different stimulus types.

Phoneme discrimination was also investigated in older infants, i.e., in 6-month-old and 12-month-old infants with respect to differences relevant in the particular target language or not [15]. Infants at 6 months responded with a negative deflection between 300 and $500 \mathrm{~ms}$ to the acoustical change whereas 12-months-old infants responded with a negativity as a function of the phoneme relevant in the target language. In this study infants were tested while being awake.

\section{CONCLUSION}

Given the different states of alertness in the various infant studies it is not unlikely that the frontal negativity present in the time range between 300 and $900 \mathrm{~ms}$ in young infants reflects processes that require an alert cognitive state. The conclusion that this negativity is an indication of cognitive aspects of mismatch discrimination is compatible with the notion that the late negativity observed in early infancy has an MMN-like function [21]. The positivity in response to a mismatch, in contrast, may rather reflect a precognitive brain response.

\section{REFERENCES}

1. Näätänen R, Tervaniemi M, Sussman E et al. Trends Neurosci 24, 283-288 (2001).

2. Näätänen R and Winkler I. Psychol Bull 6, 826-859 (1999).

3. Escera C, Alho K, Schroger E and Winkler I. Audiol Neuro-Otol 5, 151-166 (2000).

4. Giard MH, Perrin F, Pernier J and Bouchet P. Psychophysiol 27, 627-640 (1990).

5. Paavilainen $\mathrm{P}$, Cammann R, Alho K et al. Event-related potentials to pitch change in an auditory stimulus sequence during sleep. In: Johnson R, Rohrbaugh JW and Parasuraman R, eds. Current Trends in Event-related Potential Research (EEG supplement 40). Amsterdam: Elsevier; 1987, pp. 246-255.

6. Nielsen-Bohlman L, Knight RT, Woods DL and Woodward K. Electroencephalogr Clin Neurophysiol 79, 281-290 (1991).

7. Näätänen $R$ and Lyytinen $H$. Mismatch negativity in sleep. In: Ogilvie RD and Harsh JR (eds). Sleep onset: Normal and Abnormal Processes. Washington, DC: American Psychological Association; 1994, pp. 339-349.

8. Loewy DH, Campbell KB and Bastian C. Electroencephalogr Clin Neurophysiol 98, 493-501 (1996).

9. Loewy DH, Campbell KB, de Lugt DR et al. Clin Neurophysiol 111, 863-872 (2000).

10. Sallinen M and Lyytinen H. Psychophysiol 34, 694-702 (1994).

11. Nittono H, Momose D and Hori T. Clin Neurophysiol 112, 732-739 (2001).

12. Näätänen R. Attention and Brain Function. Hillsdale, NJ: Lawrence Erlbaum; 1992.

13. Winter O, Kok A, Kenemans JL and Elton M. Electroencephalogr Clin Neurophysiol 96, 398-412 (1995).

14. Näätänen R, Lehtokowski A, Lennes $M$ et al. Nature 385, 432-434 (1997).

15. Cheour M, Ceponiene R, Lehtokoski A et al. Nature Neurosci 1, 351-353 (1998).

16. Dehaene-Lambertz G. J Cogn Neurosci 12, 449-460 (2000).

17. Pihko E, Leppänen PHT, Eklund KM et al. Neuroreport 10, 901-905 (1999).

18. Leppänen PHT, Pihko E, Eklund KM and Lyytinen H. Neuroreport 10, 969-973 (1999).

19. Nittono H, Momose D and Hori T. Clin Neurophysiol 112, 732-739 (2001).

20. Cheour M, Alho K, Saino K et al. Dev Neuropsychol 13, 167-174 (1997).

21. Cheour M, Alho K, Ceponiené R et al. Int J Psychophysiol 29, 217-226 (1998).

22. Kraus N, McGee T, Carrell T et al. J American Acad Audiol 4, 238-248 (1993).

\footnotetext{
Acknowledgments: We want to thank Kai Alter for his advice in preparing the stimulus materials and Christina Rügen for recording the ERP data. This study was supported by the Deutsche Forschungsgemeinschaft (German Research Foundation, DFG) (FR-519/

I8-I) as part of the Research Group 38I Frühkindliche Sprachentwicklung und spezifische Sprachentwicklungsstörungen.
} 